\title{
0407 THE IMPACT OF AREA SOCIOECONOMIC INEOUITY ON SERIOUS INJURY IN VICTORIA
}

A Clapperton*, E Cassell Correspondence: Monash University Accident Research Centre, Building 70, Monash University, Victoria, 3800, Australia

\subsection{6/ip.2010.029215.407}

Social factors such as socioeconomic status (SES) are increasingly being viewed as fundamental causes of premature death and illness and there is a growing body of evidence linking residential location with health outcomes.

The aim of this study was to investigate the relationship between the SES of the area in which a person lives and their risk of hospitalisation for injury.

Local government areas (LGAs) in Victoria are assigned to SES deciles by the Australian Bureau of Statistics based on a composite measure of SES devised by the Bureau. For this research the deciles were combined to form quintiles. All individuals living in an LGA were assigned the same SES ranking ranging from 1 to 5 (1=most disadvantaged through $5=$ least disadvantaged) and their risk of injury compared overall and in broad age groups.

The effect of area SES on injury risk varied substantially by age, gender and injury cause. Injury hospital admission rates were generally lowest in the least disadvantaged quintile of LGAs but not often highest in the most disadvantaged quintile of LGAs. The regression analysis showed that, overall, persons living in the more disadvantaged areas were significantly more likely to be hospitalised than persons in the least disadvantaged areas for transport injury (incident rate ratio range 1.18-1.36), machinery-related injury (1.50-1.83), fire/burns/ scalds (1.25-1.61) and assaultive injury (1.20-1.77). These injury causes account for $20 \%$ of injury hospital admissions. 